\title{
Neuraminidase deficiency: case report and review of the phenotype
}

\author{
I D YOUNG*, E P YOUNG $\dagger$, J MOSSMAN†, A R FIELDER , AND J R MOORE* \\ From the Departments of Child Health* and Ophthalmology $\ddagger$, Leicester Royal Infirmary, Leicester; and \\ the Department of Clinical Biochemistry, Institute of Child Health, London.
}

\begin{abstract}
SUMMARY A 12 year old boy with neuraminidase deficiency (sialidosis, mucolipidosis I) is described. His clinical features included coarse facies, cherry red spot, ataxia, myoclonus, and dysotosis multiplex. The level of neuraminidase activity in cultured fibroblasts was very low and intermediate levels were observed in both parents. The clinical disorders associated with neuraminidase deficiency are reviewed.
\end{abstract}

In 1968 two reports were published describing children who showed features of both a mucopolysaccharidosis and a sphingolipidosis. ${ }^{12}$ Initially described as a lipomucopolysaccharidosis ${ }^{\prime}$ this entity was later classified as mucolipidosis I when the term 'mucolipidosis' was introduced as a common designation for a number of progressive disorders clinically related to both the mucopolysaccharidoses and the sphingolipidoses. ${ }^{3}$

Subsequent studies revealed that patients with mucolipidosis I showed excessive intracellular accumulation and urinary excretion of sialic acid containing molecules in association with a neuraminidase (=sialidase) deficiency. ${ }^{4}$ The demonstration that other patients with a somewhat different clinical course also showed a deficiency of neuraminidase activity prompted the publication of a comprehensive review and classification of the different forms of neuraminidase deficiency, also known as sialidosis. ${ }^{5}$ This classification incorporated several different entities, including mucolipidosis I, Goldberg's syndrome, ${ }^{6}$ and the cherry red spotmyoclonus syndrome.

We now report the findings in a 12 year old boy, who appears to be the first patient of Indian origin in whom sialidosis has been documented. We also review the clinical features of published cases of neuraminidase deficiency and hope that this brief overview will be of value for those confused by existing terminology.

\section{Case report}

The proband, a male aged 12 years, is the second

Received for publication 24 September 1985.

Revised version accepted for publication 4 February 1986. child of healthy unrelated Indian parents. His older brother is healthy and there is no other relevant family history. He was born at term with birth weight $2 \cdot 1 \mathrm{~kg}$. He was first investigated at 18 months of age because of short stature and delayed milestones. He first walked at 20 months and began

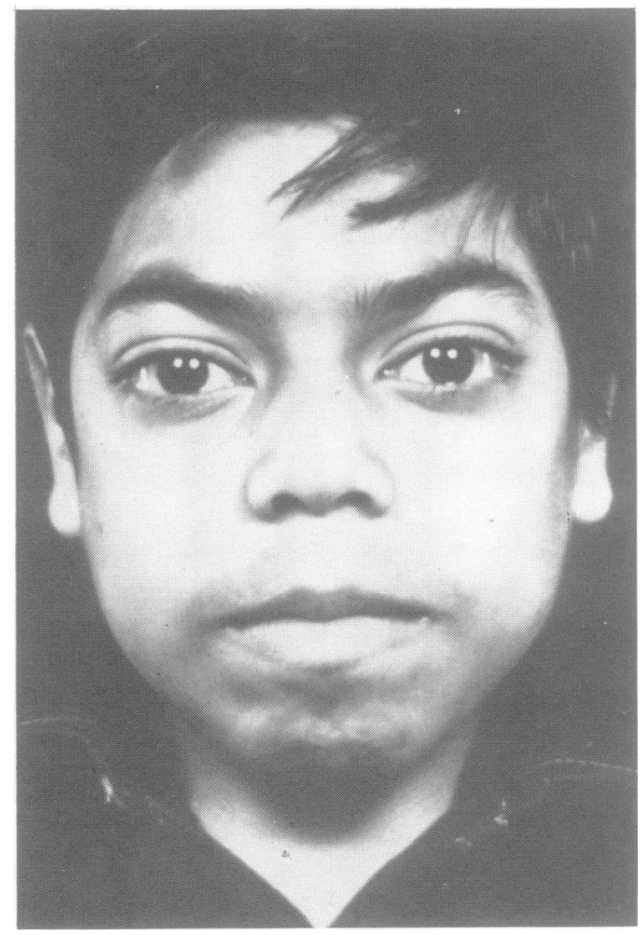

FIG 1 Facial view of the patient aged 12 years. 
talking at two years. At three years of age he was noted to have coarse facial features and a diagnosis of a mucopolysaccharidosis was considered, although there was no hepatosplenomegaly or excess mucopolysacchariduria. Formal developmental assessment at that time revealed an IQ of approximately 75 .

He was reassessed at the age of nine years because of poor school performance and failing vision. A coarse 'Hurleroid' facies was noted, a skin biopsy taken, and appropriate biochemical investigations initiated (results below). Using the Wechsler Intelligence Test for Children his full scale IQ was assessed at 67.

His first grand mal convulsion occurred at the age of 11 years and since then he has had frequent myoclonic jerks, particularly at night. Repeat IQ assessment at 11 years of age indicated mild deterioration in intellectual skills with a full scale IQ of 55 .

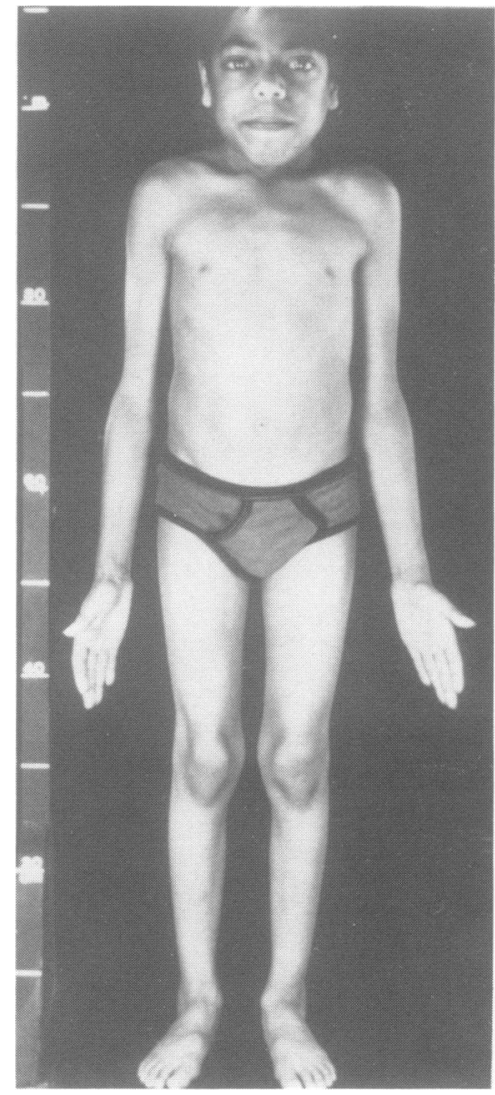

FIG $2 A P$ and lateral views of the patient at 12 years.
On examination at the age of 12 years his height $(118.5 \mathrm{~cm})$, weight $(20.5 \mathrm{~kg})$, and head circumfer ence $(48 \mathrm{~cm})$ all fell well below the 3 rd centile. Fifs facies was coarse with prominent lips, large tongu्E, and gingival hypertrophy (figs 1 and 2). There limitation of abduction at the shoulders and $\widehat{\nabla} \mathrm{f}$ external rotation at the hips with mild limitation $\frac{\text { of }}{\mathrm{g}}$ extension at elbows and knees. Movements at other joints were normal. The liver and spleen were not enlarged. Neurological findings included ataxia with an intention tremor, mild generalised hypotonis? ankle clonus, extensor plantar responses, and fie vertical nystagmus.

Visual acuity was $6 / 60$ in each eye with a low myopic correction. Both corneae exhibited veisy faint opacification of the superficial stroma. Othier ocular findings included extensive dot lens opacities clustered around the lens nucleus, bilateral op atrophy, and cherry red spots (fig 3). Visual fietd testing showed a central scotoma bilaterally. Oculor

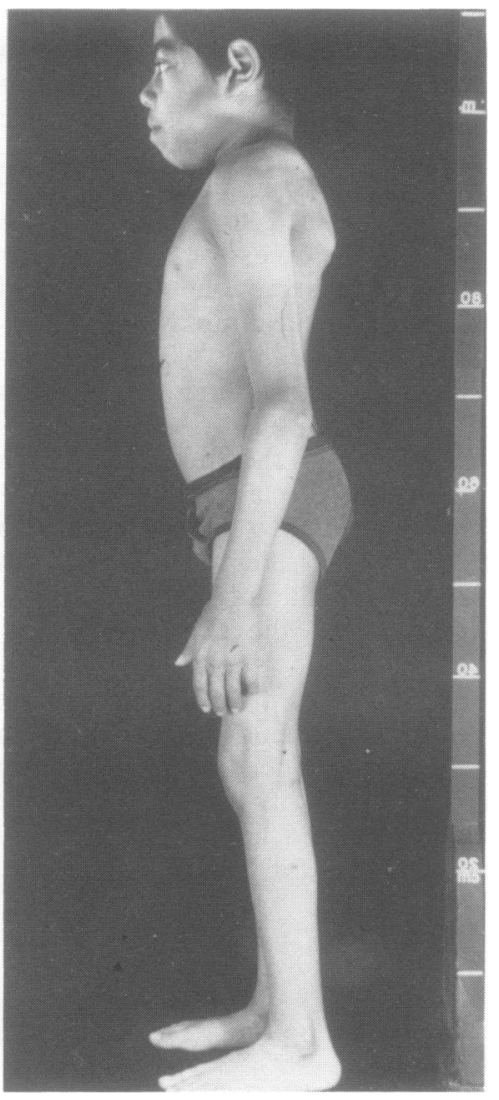




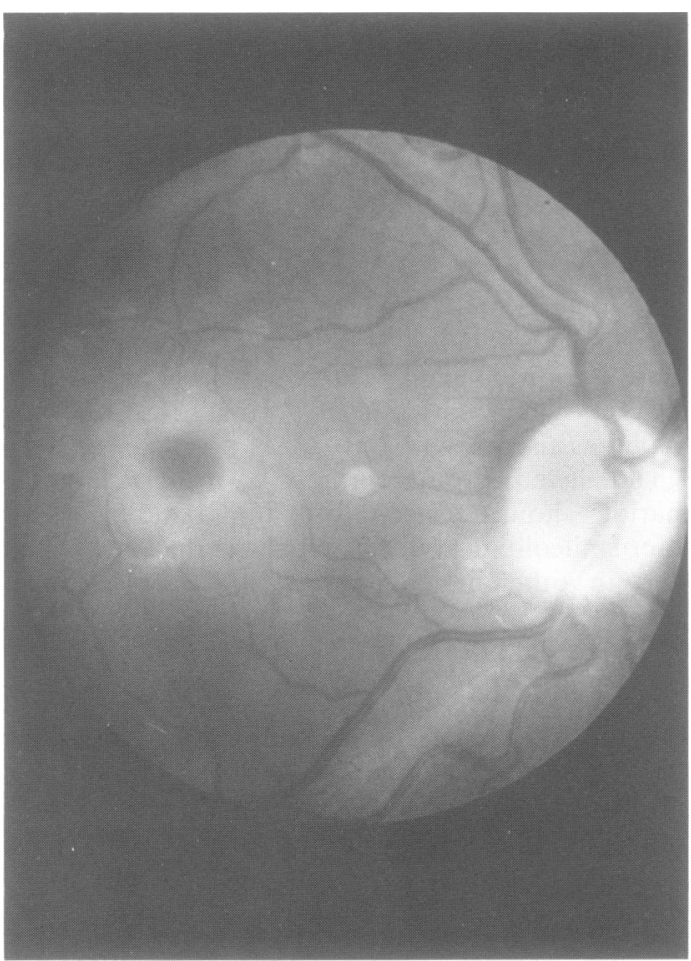

FIG 3 View of the right fundus showing cherry red spot and optic atrophy.

movements were full but there were bursts of medium rate fine vertical nystagmus. Colour perception was grossly abnormal across the spectrum. The visually evoked potential to a flash stimulus showed a delayed major positive peak.

Audiology revealed a mild bilateral conductive hearing loss.

Skeletal survey showed flattening of the lumbar vertebrae with anterior tonguing and irregular end plates (fig 4), a J shaped pituitary fossa (fig 5), a small irregular left femoral epiphysis (fig 6), and mild pointing of the proximal end of the metacarpals (fig 7).

\section{Biochemical investigations}

METHODS

Urine

Random urine specimens were preserved with merthiolate (BDH Thiomersal, 1 in $10000 \mathrm{w} / \mathrm{v}$ ) and stored at $-20^{\circ} \mathrm{C}$ before analysis.

Glycosaminoglycans (GAGs) were measured on two separate occasions, at the ages of nine and
12 years, using Alcian Blue $8 \mathrm{GX} .{ }^{8}$ For identification of individual GAGs, Alcian Blue precipitated GAGs were separated by two dimensional electrophoresis on cellulose acetate and visualised with Alcian Blue. ${ }^{9}$

Oligosaccharides were separated by thin layer chromatography on commercial silica gel plates and visualised with orcinol. ${ }^{10}$

Urine $(50 \mu \mathrm{l})$ was added to ethanol $(200 \mu \mathrm{l})$, centrifuged, and the supernatant evaporated to dryness. The resulting residue was dissolved in $20 \mu$ methanol: water (1:1), applied to the TLC plate, and developed twice to $10 \mathrm{~cm}$ in n-butanol:acetic acid:water (2:1:1).

\section{Skin fibroblasts}

Fibroblasts were cultured as previously described ${ }^{11}$ except that the culture medium was Ham's F10 containing $12 \%$ fetal calf serum. Cells were harvested two days after confluency using trypsin $(0 \cdot 25 \% \mathrm{w} / \mathrm{v})$.

\section{Enzyme assays}

The fibroblasts were hand homogenised in water and the neuraminidase assayed within two hours of homogenisation according to the method of Lake et al. ${ }^{12} \quad \beta$ galactosidase was assayed as described previously, ${ }^{13}$ except that the incubation temperature

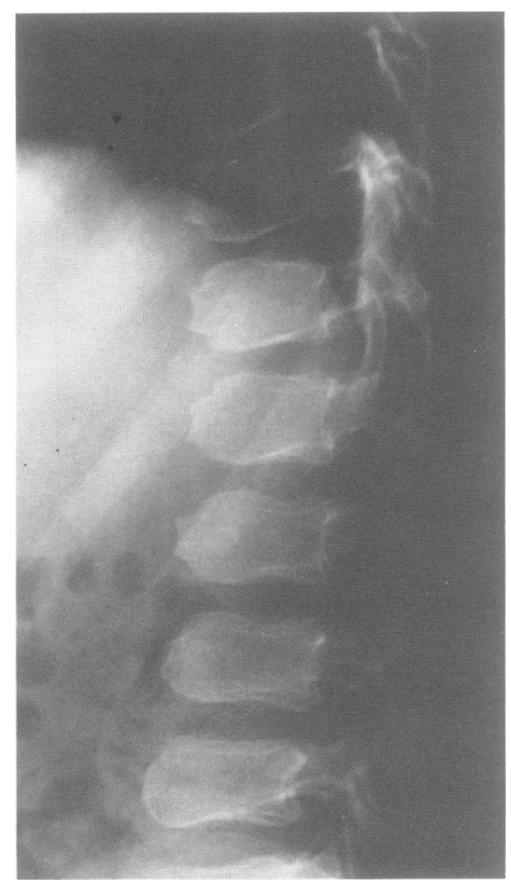

FIG 4 Lateral view of the spine at 12 years. 


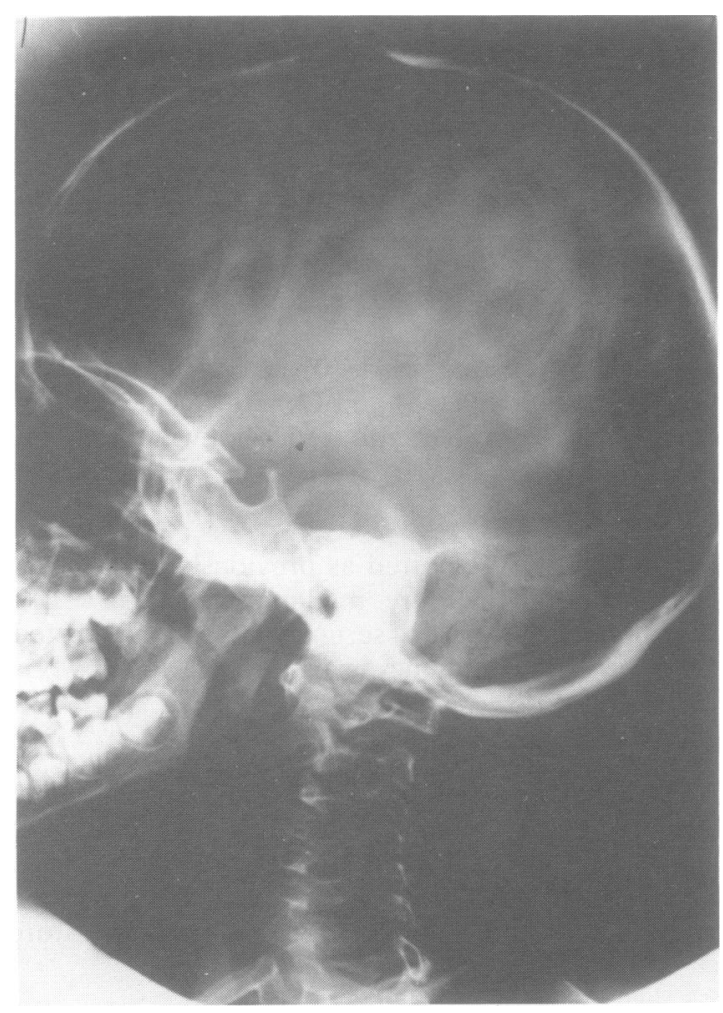

FIG 5 Lateral view of the skull at 12 years. was $37^{\circ} \mathrm{C}$ and the assay contained $0.1 \%$ huma $\stackrel{\mathbb{\pi}}{n}$ albumin. The protein content of the homogenate was determined by the method of Lowry et al. ${ }^{4}$

RESULTS

Urine

Urinary GAG/creatinine ratios fell within the normal range (age related) on both occasions. Characterise ation of individual GAGs showed chondroitin suFphate as the major component, with heparan sulphate and very small amounts of dermatan and kerata sulphates also present.

Thin layer chromatography of urinary oligosact charides showed a strongly staining band characte istic of mucolipidosis I. ${ }^{15}$ This pattern differs from that seen in other mucolipidoses and GM1 ganglios sidosis (fig 8).

\section{Enzyme activities}

The results of neuraminidase and $\beta$ galactosidase activities are shown in table 1 . Two separate subcupe tures were assayed for the patient and both parent Neuraminidase activity in cultured fibroblasts was consistently very low in the proband and in the predicted heterozygous range in both parents.

\section{Discussion}

Clinical and biochemical details of dysmorphie patients with primary neuraminidase deficiency are summarised in table 2. At least five different clinical

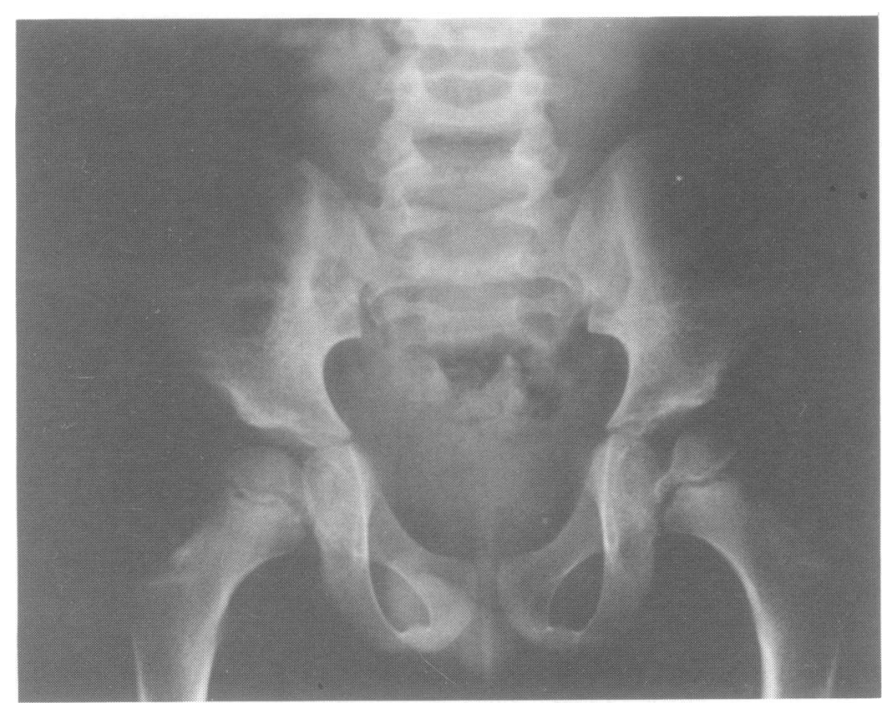




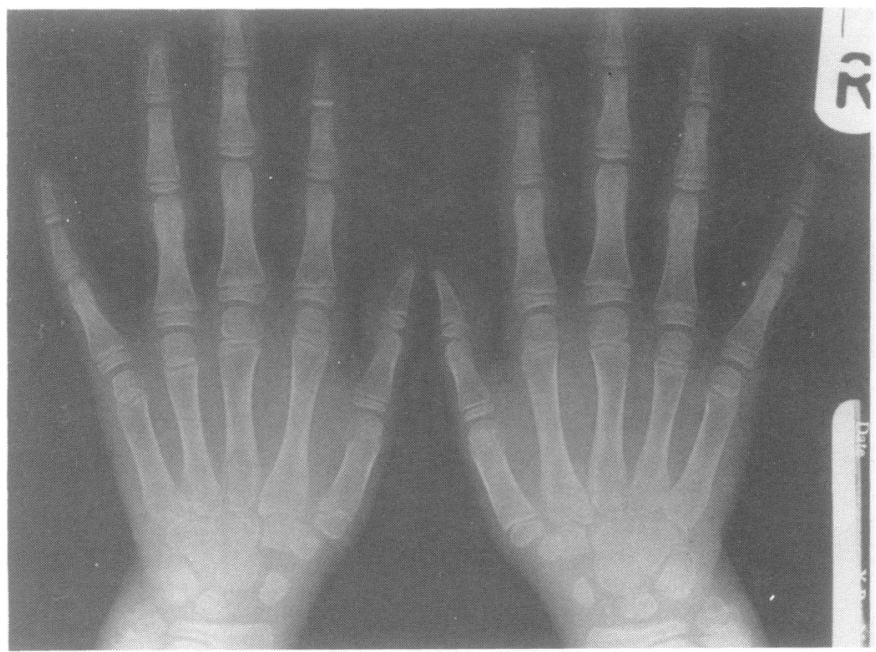

FIG 7 Radiograph of the hands at 12 years.

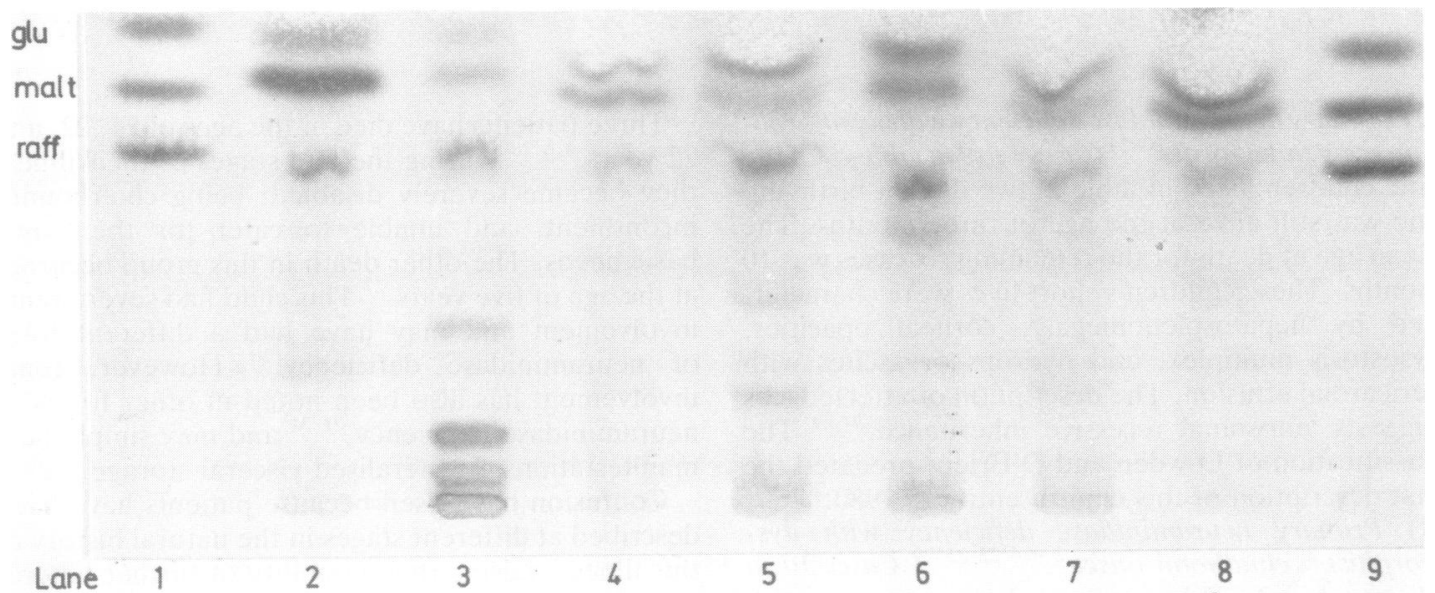

FIG $8 T L C$ of urinary oligosaccharides in n-butanol:acetate acid:water (2:1:1). Lanes 1 and 9: std glucose, maltose, raffinose; lane 2: normal; lane 3: GMI gangliosidosis; lane 4: ML I; lane 5: the proband; lane 6: $M L$ II; lane 7: ML III; lane 8: $M L I V$.

TABLE 1 Enzyme activities in two separate subcultures for patient and parents.

\begin{tabular}{|c|c|c|}
\hline & \multicolumn{2}{|c|}{ linzyme activities in cultured fibroblasts } \\
\hline & Néuraminidase & P' galactosidase \\
\hline \multirow[t]{2}{*}{ Paticnt } & 0.77 & 818 \\
\hline & $11 \cdot 3.3$ & 1.3 .36 \\
\hline \multirow[t]{2}{*}{ Mother } & $3 \cdot 1$ & 111.56 \\
\hline & $3 \cdot 2$ & 997 \\
\hline \multirow[t]{2}{*}{ Father } & $3 \cdot x$ & 935 \\
\hline & 3.9 & 946 \\
\hline Normal range $(n=31)$ & $6-32$ & $360-1678$ \\
\hline Mean $\pm S I)$ & $12 \cdot 1 \pm 4 \cdot 6$ & $6(15 \pm 245$ \\
\hline
\end{tabular}

$\mathrm{nmol} / \mathrm{h} \mathrm{mg}$ protcin. entities can be recognised in which neuraminidase deficiency occurs. These are summarised below.

(I) Primary neuraminidase deficiency without dysmorphism. ${ }^{\text {(1)-19) }}$ This condition represents the cherry red spot-myoclonus syndrome ${ }^{7}$ and was classified by Lowden and O'Brien ${ }^{5}$ as sialidosis type 1. These patients usually present in the second decade with decreased visual acuity, myoclonus. or gait abnormalities. Vision and neurological function show slow deterioration. Intellect and appearance are normal and survival beyond 30 years is usual. Affected sibs of both sexes, ${ }^{716-19}$ parental consanguinity, ${ }^{78}$ and heterozygous levels of neuraminidase in parents ${ }^{17} 19$ indicate that inheritance is autosomal recessive. 
TABLE 2 Published cases of neuraminidase deficiency with dysmorphism.

\begin{tabular}{|c|c|c|c|c|c|c|c|c|c|c|c|c|}
\hline \multirow[t]{2}{*}{ Case } & \multirow[t]{2}{*}{ No } & \multirow[t]{2}{*}{ Reference } & \multirow[t]{2}{*}{ Consanguinity } & \multirow[t]{2}{*}{ Sex } & \multirow[t]{2}{*}{$\begin{array}{l}\text { Age at } \\
\text { death }\end{array}$} & \multirow[t]{2}{*}{$\begin{array}{l}\text { Short } \\
\text { stature }\end{array}$} & \multicolumn{2}{|c|}{$I Q$ or mental state } & \multirow{2}{*}{$\begin{array}{l}\text { Hydrops } \\
\text { or ascites }\end{array}$} & \multirow[t]{2}{*}{$\begin{array}{l}\text { Course } \\
\text { facies }\end{array}$} & \multicolumn{2}{|c|}{$\begin{array}{l}\text { Dysotosix } \\
\text { multiplex }\end{array}$} \\
\hline & & & & & & & Result & $C A$ & & & & 7 \\
\hline \multirow{3}{*}{ Sibs } & 5 & 21 & - & $\mathbf{M}$ & $1: 10 / 12$ & & & & + & + & + & \\
\hline & 6 & 22 & - & $\mathrm{F}$ & $4 / 12$ & & & & + & & & 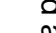 \\
\hline & 7 & 23 (case 2) & - & $\mathrm{F}$ & $2: 2 / 12$ & & & & + & + & + & c \\
\hline \multirow{2}{*}{ Sibs } & 10 & 2 & - & $\mathrm{F}$ & $15^{*}$ & + & 45 & 12 & & \pm & + & tha \\
\hline & $(11$ & 25 & + & $\mathbf{M}$ & $20^{*}$ & + & 58 & 10 & & + & + & \\
\hline \multirow[t]{5}{*}{ Sibs } & & 6 (IV.4) & & & & & & & & & & c \\
\hline & 12 & 6 (IV.9) & + & $\mathbf{F}$ & 22 & & & & & + & + & $=$ \\
\hline & 13 & 4 (DF) & - & $\mathbf{M}$ & $12^{*}$ & + & 45 & 12 & & + & + & \\
\hline & 14 & 4 (RH) & - & $\mathbf{M}$ & 21 & + & 75 & 12 & & + & + & \\
\hline & 15 & 26 & & $\mathbf{M}$ & $8^{*}$ & + & $2: 2 / 12$ & $2: 5 / 12$ & & + & + & \\
\hline \multirow[t]{5}{*}{ Sibs } & 16 & 27 & - & $\mathbf{M}$ & 5 & + & Retarc & & & + & + & \\
\hline & 19 & 23 (case 1) & & $\mathrm{F}$ & $6^{*}$ & + & $1: 3 / 12$ & $1: 8 / 12$ & & + & + & \\
\hline & 20 & 23 (case 3) & - & $\mathrm{F}$ & $2^{*}$ & & $1: 6 / 12$ & 2 & & + & + & \\
\hline & 21 & 29 & - & $\mathbf{M}$ & $5^{*}$ & + & 50 & 5 & & + & + & \\
\hline & & & - & M & $12^{*}$ & + & 67 & 9 & & + & + & \\
\hline
\end{tabular}

(2) Primary neuraminidase deficiency with dysmorphism, congenital form. ${ }^{20-24}$ Cases 1 to 9 in table 2 . Of the nine children listed in table 2 , two died at birth and one was still alive at the age of three months. The mean age at death for the remaining six cases was 10 months. These children's short lives were characterised by hepatosplenomegaly, corneal opacities, dysostosis multiplex, and hydrops or ascites with pericardial effusion. The description of affected sibs suggests autosomal recessive inheritance. ${ }^{20} 24$ The classification of Lowden and O'Brien ${ }^{5}$ predated the first description of this clinical entity in $1980{ }^{20} 21$

(3) Primary neuraminidase deficiency with dysmorphism, childhood onset. ${ }^{2462325-29}$ Cases 10 to 21 in table 2. This group includes patients with mucolipidosis I, the infantile form of type II sialidosis, ${ }^{5}$ and Goldberg's syndrome. ${ }^{6}$ (In the original report Goldberg's patient had low $\beta$ galactosidase activity in skin, but subsequent studies ${ }^{25}$ showed normal $\beta$ galactosidase activity in cultured fibroblasts.)

Affected children present in early childhood with mild developmental delay but it may be several years before the diagnosis is suspected. Disproportionate short stature with relatively long legs is characteristic. By the age of 10 years these children show a coarse facies and at around this time visual and neurological problems develop. Radiographs reveal dysostosis multiplex affecting the skull, ribs, clavicles, pelvis, hands, and spine. Intellect is usually only mildly impaired initially so that affected children are able to attend normal school until adolescence, when intellectual skills deteriorate.
Three patients have died at the ages of 21,22 , and. $\stackrel{\infty}{\nu}$ 22 years. ${ }^{4628}$ During the late stages of their illness they became severely disabled, being chairbound, incontinent, and unable to cater for their own basic needs. The other death in this group occurred at the age of five years. ${ }^{27}$ This child had severe renal ${ }_{\circ}^{\circ}$ involvement and may have had a different form $\underset{\Rightarrow}{\Rightarrow}$ of neuraminidase deficiency. ${ }^{30}$ However, renalo윽 involvement has also been noted in other forms of neuraminidase deficiency, ${ }^{21}{ }^{31}$ and may simply be a官 manifestation of generalised visceral storage.

Confusion has arisen because patients have been described at different stages in the natural history of this illness, raising the possibility of further hetero- 3 geneity. For example, review of the cases in table $2 \delta$ indicates that they could be divided into two groups based on the presence or absence of hepato- 0 splenomegaly. Long term study of other patients is necessary to clarify whether further subdivision is justified.

(4) Combined neuraminidase/ $\beta$ galactosidase defi- $N$ ciency, infantile onset. ${ }^{31-34}$ This relatively rare N condition presents either at birth with hydrops or N ascites $^{32} 33$ or in infancy with coarse facies, hepato- $\omega$ splenomegaly, and skeletal changes. ${ }^{31} 34$ In a recent classification of the sialidoses, Spranger ${ }^{35}$ subdivided $\stackrel{\circ}{\complement}$ patients in this group into early and late infantile onset. Andria et $a b^{34}$ suggested the term 'galacto-sialidosis' for combined neuraminidase/ $\beta$ galacto- -0 sidase deficiency and concluded that the infantile $\overrightarrow{\mathbb{D}}$ group could be subdivided into mild and severe. The $\frac{\mathcal{Q}}{\mathbb{Q}}$ prognosis in mildly affected patients appears good: $\stackrel{\mathbb{Q}}{\circ}$ the oldest patient described ${ }^{34}$ had normal growth and 


\begin{tabular}{|c|c|c|c|c|c|c|c|c|c|c|c|c|}
\hline \multicolumn{2}{|c|}{ Enlarged } & \multirow{2}{*}{\multicolumn{2}{|c|}{ Myoclonus Ataxia }} & \multirow[t]{2}{*}{$\begin{array}{l}\text { Cherry } \\
\text { red spot }\end{array}$} & \multirow[t]{2}{*}{$\begin{array}{l}\text { Lens } \\
\text { opacities }\end{array}$} & \multirow[t]{2}{*}{$\begin{array}{l}\text { Corneal } \\
\text { opacities }\end{array}$} & \multicolumn{3}{|c|}{$\begin{array}{l}\text { Neuraminidase } \\
\text { in fibroblasts }\end{array}$} & \multicolumn{3}{|c|}{$\begin{array}{l}\beta \text { galactosidase } \\
\text { in fibroblasts }\end{array}$} \\
\hline Liver & Spleen & & & & & & Patient & Father & Mother & Patient & Father & Mother \\
\hline+ & + & & & & & & $\downarrow \downarrow$ & $\downarrow$ & $\downarrow$ & $\mathrm{N}$ & & \\
\hline+ & + & & & - & & - & $\downarrow \downarrow$ & $\downarrow$ & $\downarrow$ & $60 \%$ & & \\
\hline+ & + & & & & & & & & & $\mathrm{N}$ & & \\
\hline+ & + & & & & & + & $\downarrow \downarrow$ & & & $\mathrm{N}$ & & \\
\hline+ & + & & & & & & $\downarrow \downarrow$ & $\downarrow$ & & $\mathrm{N}$ & & \\
\hline+ & + & + & + & + & & + & & & & & & \\
\hline \multirow[t]{2}{*}{-} & - & + & & + & + & + & $\downarrow \downarrow$ & & $\downarrow$ & $\mathrm{N}$ & & $\mathrm{N}$ \\
\hline & & + & & & & & & & & & & \\
\hline \pm & - & + & & + & + & + & $\downarrow$ & & & $\mathrm{N}$ & & \\
\hline \pm & - & + & + & + & - & - & & $\downarrow$ & $\downarrow$ & $\mathrm{N}$ & & \\
\hline+ & + & - & - & + & + & & $\downarrow \downarrow$ & $\downarrow$ & $\downarrow$ (In WBC) & & & \\
\hline+ & + & & & & + & + & $\downarrow \downarrow$ & & (In WBC) & $\mathrm{N}$ & & \\
\hline \multirow[t]{2}{*}{+} & + & & & & + & + & $\downarrow \downarrow$ & & (In WBC)I & $\mathrm{N}$ & & \\
\hline & & + & \pm & + & & - & $\downarrow$ & $\downarrow$ & & $\mathrm{N}$ & & \\
\hline+ & + & & & + & - & - & $\downarrow \downarrow$ & & & $\mathrm{N}$ & & \\
\hline+ & + & & & - & + & - & $\downarrow \downarrow$ & $\downarrow$ & $\downarrow$ & $\mathrm{N}$ & & \\
\hline+ & - & - & - & + & - & - & $\downarrow \downarrow$ & $\downarrow$ & $\downarrow$ & $\mathrm{N}$ & & \\
\hline- & - & + & + & + & + & + & $\downarrow \downarrow$ & $\downarrow$ & $\downarrow$ & $\mathrm{N}$ & $N$ & $N$ \\
\hline
\end{tabular}

$+=$ Present. $-=$ absent. $\pm=$ mild. $\downarrow \downarrow=$ very low. $\downarrow=$ heterozygote level. $\mathrm{N}=$ normal. CA=chronological age in years. ${ }^{*}=$ still alive.

intellect at the age of eight years.

(5) Combined neuraminidase/ $\beta$ galactosidase deficiency, juvenile onset. ${ }^{36-39}$ These patients usually present in their early teens with gait disturbance, myoclonus, and failing vision. They are of moderately short stature and have coarse facial features. Skeletal changes are most apparent in the lumbar vertebrae. Angiokeratoma occur commonly. Features which distinguish this entity from primary neuraminidase deficiency with dysmorphism and childhood onset (type 3 in this classification) are its later age of onset, longer survival, relatively normal intellect, milder skeletal changes, ethnic distribution (almost entirely Japanese), and associated $\beta$ galactosidase deficiency.

Confirmation that these disorders represent discrete entities comes from complementation studies. Hoogeveen et al ${ }^{41}$ demonstrated complementation between cells cultured from patients from groups 1 and 4,3 and 4,1 and 5, and 3 and 5 . Complementation did not occur using cells from patients from groups 1 and 3 , or 4 and 5 . These observations have been confirmed by others. ${ }^{41} 42$ D'Azzo et $a l^{43}$ speculated that the basic defect in combined neuraminidase/ $\beta$ galactosidase deficiency lies in a glycoprotein normally required to protect these two enzymes against intralysosomal degradation. This contrasts with the defect in mucolipidosis types II and III in which there is believed to be a lack of recognition markers for targeting enzymes to lysosomes, so that activities of all lysosomal enzymes are low in cultured fibroblasts but raised in serum.
Thus, in summary, neuraminidase deficiency may present as at least five different disease entities. Affected sibs, parental consanguinity, and heterozygous levels in parents indicate that all of these entities show autosomal recessive inheritance. Prenatal diagnosis has been recorded for several types $^{201} 32$ and should in principle be possible for all forms of neuraminidase deficiency. ${ }^{44}$ It is hoped that this short review will enhance recognition of neuraminidase deficiency and enlighten those who, like the authors, find the nomenclature confusing.

The authors are grateful to Dr R K Turner for providing details of the developmental assessments and to Mrs Susan Kenney for typing the manuscript.

\section{Note added in proof}

Recent studies $^{45}$ have revealed differences in the biosynthesis of the defective 'protective protein' between the early infantile, late infantile, and juvenile forms of combined neuraminidase/ $\beta$ galactosidase deficiency.

\section{References}

' Spranger J, Wiedemann HR. Tolksdorf M. Graucob E. Caesar R. Lipomucopolysaccharidose. Eine neue speicherkrankheit. $Z$ Kinderheilkd 1968:103:285-306.

2 Berard M. Toga M. Bernard R. Dubois D. Mariani R. Hassoun J. Pathological findings in one case of neuronal and mesenchymal storage disease. Its relationship to lipidoses and to mucopolysaccharidoses. Pathol Eur 1968:3:172-83. 
${ }^{3}$ Spranger JW, Wiedemann HR. The genetic mucolipidoses. Diagnosis and differential diagnosis. Humangenetik 1970;9: 113-39.

${ }^{4}$ Spranger J, Gehler J, Cantz M. Mucolipidosis I-a sialidosis. Am J Med Genet 1977;1:21-9.

${ }^{5}$ Lowden JA, O'Brien JS. Sialidosis: a review of human neuraminidase deficiency. Am J Hum Genet 1979:31:1-18.

6 Goldberg MR, Cotlier E, Fichenscher LG, Kenyon K, Enat R, Borowsky SA. Macular cherry red spot, corneal clouding, and $\beta$-galactosidase deficiency. Arch Intern Med 1971:128:387-98.

7 Durand P, Gatti R. Cavalieri S, et al. Sialidosis (mucolipidosis I). Helv Paediatr Acta 1977;32:391-400.

${ }^{8}$ Whiteman P. The quantitative determination of glycosaminoglycans in urine with Alcian Blue 8GX. Biochem J 1973;131: 351-7.

" Whiteman P, Henderson $\mathrm{H}$. A method for the determination of amniotic fluid glycosaminoglycans and its application to the prenatal diagnosis of Hurler and Sanfilippo diseases. Clin Chim Acta 1977;79:99-105.

11 Tsai MY, Marshall JC. Screening for urinary oligosaccharides and simple sugars by thin layer chromatography. Med Lab Sci 1979;36:85-90.

1 Young EP, Willcox P, Whitfield AE, Patrick AD. Variability of acid hydrolase activities in cultured skin fibroblasts and amniotic cells. J Med Genet 1975;12:224-9.

12 Lake BD, Milla PJ, Taylor DSI, Young EP. A mild variant of mucolipidosis type 4 (ML4). Birth Defects 1982;18(6):391-404.

13 Young EP, Ellis RB, Patrick AD. Lcukocyte $\beta$-galactosidase activity in GMI-gangliosidosis. Pediatrics 1972;50:502-3.

${ }^{14}$ Lowry OH, Rosebrough NJ, Farr AL, Randall RJ. Protcin measurement with the Folin phenol reagent. J Biol Chem 1951;193:265-75.

15 Sewell AC. An improved thin layer chromatographic method for urinary oligosaccharide screening. Clin Chim Acta 1979;92: 411-4.

${ }^{16}$ Rapin I, Goldfischer S, Katzman R, Engel J, O'Brien JS. The cherry-red spot-myoclonus syndrome. Ann Neurol 1978;3: 234-42.

17 Thomas GH, Tipton RE, Ch'ien LT, Reynolds LW, Miller CS Sialidase ( $\alpha-\mathrm{N}$-acetyl neuraminidase) deficiency: the enzyme defect in an adult with macular cherry-red spots and myoclonus without dementia. Clin Genet 1978;13:369-79.

18 Thomas PK, Abrams JD, Swallow D, Stewart G. Sialidosis type 1: cherry red spot-myoclonus syndrome with sialidase deficiency and altered clectrophoretic mobilities of some enzymes known to be glycoproteins. J Neurol Neurosurg Psychiatry 1979;42: 873-80.

${ }^{19}$ O'Brien JS. The cherry red spot-myoclonus syndrome a newly recognised inherited lysosomal storage disease due to acid neuraminidase deficiency. Clin Genet 1978;14:55-60).

20) Johnson WG, Thomas GH, Miranda AF, et al. Congenital sialidosis, biochemical studies, clinical spectrum in four sibs: two successful prenatal diagnoses. Am J Hum Genet 1980;32:43A.

21 Aylesworth AS. Thomas GH, Hood JL, Malouf N, Libert J. A severe infantile sialidosis: clinical biochemical and microscopic features. J Pediutr 1980;96:662-8.

22 Riches WG, Smuckler EA. A severe infantile mucolipidosis. Arch Pathol Lab Med 1983;107:147-52.

${ }^{2.3}$ Kelly TE, Bartoshesky L, Harris DJ, McCanley GK, Feingold M, Schott G. Mucolipidosis I (acid ncuraminidase deficiency). Am J Dis Child 1981;135:703-8.

${ }^{24}$ Laver J, Fried K, Beer SI, et al. Infantile lethal neuraminidase deficiency (sialidosis). Clin Genet 1983;23:97-101.

25 Thomas GH, Goldberg MF, Miller CS, Reynolds LW. Ncuraminidase deficiency in the original patient with the Goldberg syndrome. Clin Genet 1979;16:323-30.

26 Maroteaux P. Poissonnicr M. Tondeur M. Strecker G, Lemonnier M. Sialidose par deficit en alpha (2-6) neuraminidase sans attcinte neurologique. Arch Fr Pediatr 1978:35:280-91

27 Maroteaux P. Humbel R, Strecker G. Michalski JC. Mande R. $\Rightarrow$ Un nouveau type de sialidose avec atteinte renale: la nephro- $\mathscr{S}$ sialidose. Arch Fr Pediatr 1978:35:819-29.

${ }^{28}$ Winter RM, Swallow DM, Baraitser M. Purkiss P. Sialidosis type 2 (acid neuraminidase deficiency): clinical and biochemical features of a further case. Clin Genet 1980;18:203-10.

29 Louis JJ, Maire I, Hermier M. Nicholas A. Guiband P. Une $\overrightarrow{\mathbb{D}}$ observation de mucolipidose de type I par deficit primaire en alpha D neuraminidase. J Genet Hum 1983:31:79-91. के

30) Munnich A, Maroteaux P. Nephrosialidosis. Perspect Inher $\overrightarrow{0}$ Metab Dis 1981:4:335-9.

${ }^{31}$ Okada S. Sugino H, Kato T, et al. A severe infantile sialidosis $\overrightarrow{-}$ ( $\beta$-galactosidase- $\alpha$-ncuraminidase deficiency) mimicking GM1- $\omega$ gangliosidosis type 1. Eur J Pediatr 1983;140:295-8.

32 Kleijer WJ, Hoogeveen A, Verheijen FW, et al. Prenatal diagnosis of sialidosis with combined neuraminidase and $\beta$ galactosidase deficiency. Clin Genet 1979;16:60-1.

33 Gravel RA, Lowden JA, Callahan JW, Wolfe LS, Ng Yin Kin ç NMK. Infantile sialidosis a phenocopy of type 1 GM1 ganglio- iv sidosis distinguished by genetic complementation and urinary $\mathscr{\omega}^{\infty}$ oligosaccharides. Am J Hum Genet 1979;31:669-79.

${ }^{34}$ Andria G, Strisciuglio P. Pontarelli G, Sly WS, Dodson WE. Infantile neuraminidase and $\beta$-galactosidase deficiencies (galactosialidosis) with mild clinical courses. Perspect Inher Metab Dis 1981:4:379-95.

35 Spranger J. Mucolipidosis I: phenotype and nosology. Perspect Inher Metab Dis 1981:4:303-15.

${ }^{36}$ Suzuki Y, Nakamura N, Fuknoka K, Shimada Y, Uono M. $\beta-\stackrel{\infty}{V}$ galactosidase deficiency in juvenile and adult patients. Hum Genet 1977:36:219-29.

37 Okada S, Yutaka T, Kato T, et al. A case of neuraminidase

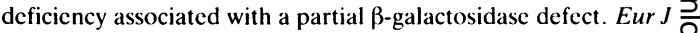
Pediatr 1979:130:239-49.

${ }^{3 *}$ Kobayashi T, Ohta M, Goto I, Tanaka Y, Kuroiwa Y. Adult type mucolipidosis with $\beta$-galactosidase and sialidase deficiency. J Neurol 1979;221:137-49.

${ }^{39}$ Loonen MCB, Reuser AJJ, Visser P. Arts WFM. Combined sialidase (ncuraminidase) and $\beta$-galactosidase deficiency. Clinical, morphological and enzymological observations in a patient. Clin Genet 1984:26:139-49.

40) Hoogeveen AT, Verheijen FW, D'Azzo A. Galjaard H. Genetic heterogeneity in human neuraminidase deficiency. Nature 1980;285:50()-2.

${ }^{4}$ Mueller OT, Shows TB. Human $\beta$-galactosidase and $\alpha$ - $\frac{\dot{\sigma}}{3}$ ncuraminidase deficient mucolipidosis genetic complementation analysis of the neuraminidase deficiency. Hum Genet 1982;60: 8 $158-62$

42 Strisciuglio P. Creek KE. Sly WS. Complementation, cross correction and drug correction studies of combined $\beta$ - $\subseteq$ galactosidase neuraminidase deficiency in human fibroblasts. Pediatr Res 1984:18:167-71.

${ }^{43}$ D'Azzo A. Hoogeveen A, Reuser JJ, Robinson D, Galjaard H. Molecular defect in combined $\beta$-galactosidase and neuramini- N dase deficiency in man. Proc Natl Acad Sci USA 1982;79: 4535-9.

${ }^{44}$ Mueller OT, Wenger DA. Mucolipidosis I: studies of sialidase N activity and a prenatal diagnosis. Clin Chim Acta 1981:109: 313-24.

45 Palmeri S, Hoogeveen AT, Verheijen FW, Galjaard H. Galactosialidosis: molecular heterogeneity among distinct $\frac{\bar{D}}{\mathscr{C}}$ clinical phenotypes. Am J Hum Genet 1986;38:137-48.

Correspondence and requests for reprints to $\mathrm{Dr} I \mathrm{D}$ Young, Department of Child Health, Clinical Scien- $\frac{\mathbb{D}}{\mathbb{D}}$ ces Building, Leicester Royal Infirmary, PO Box 65 , Leicester LE2 7LX. 